\title{
Streptococcus agalactiae from Ethiopian pregnant women; prevalence, associated factors and antimicrobial resistance: alarming for prophylaxis
}

Mucheye Gizachew ${ }^{1 *}$, Moges Tiruneh ${ }^{1}$, Feleke Moges ${ }^{1}$, Mulat Adefris $^{2}, Z_{\text {Zemene Tigabu }}^{3}$ and Belay Tessema ${ }^{1}$

\begin{abstract}
Background: Maternal Streptococcus agalactiae (Group B Streptococcus, GBS) colonization rates and its antibiotic resistance patterns provide important information useful in guiding prevention strategies. There is a paucity of evidence about GBS in the Amhara National Regional State, Ethiopia.

Objective: To determine colonization prevalence, associated risk factors, and antibiotics resistance including inducible clindamycin resistance patterns of GBS among Ethiopian pregnant women.

Methods: A prospective cross-sectional study was conducted from 1st December 2016 to 30th November 2017 at the University of Gondar Referral hospital delivery ward. Combined recto-vaginal swabs were collected from 385 pregnant women and analyzed at the University of Gondar Bacteriology Laboratory by using LIM broth and 5\% defibrinated sheep blood agar culture methods. Isolates were identified by using colony morphology, gram reaction, hemolysis, and CAMP test. Antibiotic susceptibility test was done using the disc diffusion method. Double disc diffusion method was used to identify inducible clindamycin resistance isolates. Data were analyzed by SPSS version 20 software. $p \leq 0.05$ was considered as statistically significant.

Results: The overall prevalence of maternal GBS colonization was $25.5 \%$ (95\% Cl 21-29.5\%). Experiencing meconium stained amniotic fluid $(\mathrm{AOR}=3.018,95 \% \mathrm{Cl} 1.225,7.437)$, and longer duration of premature rupture of membrane $(A O R=1.897,95 \% \mathrm{Cl} 1.014,3.417)$ were statistically significant to maternal colonization. Furthermore, GBS resistant to 0 (8.2\%), 1 (25.5\%) and $3(39.8 \%)$ or more antibiotics were identified. A D-test showed 15.2\% inducible clindamycin resistant GBS. Constitutive macrolide lincosamide-streptogramin ${ }_{B}, \mathrm{~L}$-, and M-phenotypes were also detected.
\end{abstract}

Conclusions: Maternal GBS colonization rate in this study was higher compared to the previous reports in Ethiopia. This much prevalence and antibiotics resistance results are the clue to which attention shall be given to this bacterium during management of pregnant women and the newborns.

Keywords: Antimicrobial resistance, Colonization, Prevalence, GBS, Pregnant women

*Correspondence: muchegiza@gmail.com

${ }^{1}$ Department of Medical Microbiology, School of Biomedical

and Laboratory Sciences, College of Medicine and Health Sciences,

University of Gondar, P. O. Box 196, Gondar, Ethiopia

Full list of author information is available at the end of the article 


\section{Introduction}

Streptococcus agalactiae (Group B Streptococcus; GBS) is a leading cause of neonatal infections worldwide. Mother to child transmission occurs mostly during peripartum period. Evidence on maternal colonization prevalence remains sparse in the African settings [1], specifically in Ethiopia where few studies revealed maternal colonization ranges from $7.2 \%$ [2] to $20.9 \%$ [3].

A review of 390 articles from 85 countries with a total of 299,924 pregnant women showed that the adjusted estimate for maternal GBS colonization worldwide was $18 \%$ with regional variation like lower prevalence in Southern Asia (12.5\% and Eastern Asia 11\%) [4]. The maternal colonization prevalence among the African studies was also reported as $12 \%$ in Kenya [5] to $48.2 \%$ in South Africa [6]. It is ranged from $2.3 \%$ in India [7] to $40.8 \%$ in Italy [8]. Another review of 21 studies, including 24,093 women from 13 European countries indicated that the colonization prevalence varies from $6.5 \%$ in Turkey to $36 \%$ in Denmark [9]. One global estimate study revealed that there were 33,000 cases of invasive GBS disease in pregnant or postpartum women, and 57,000 fetal infections/stillbirths. About 3.5 million preterm births may be owing to GBS, and Africa accounted for $54 \%$ of estimated cases and $65 \%$ of all fetal/infant deaths [10]. Recto-vaginal colonization of pregnant women with GBS is a major risk factor for neonatal colonization and it has to be noted that $21-35 \%$ the GBS has recovered from the recto-vaginal samples of women of reproductive age [1113]. Maternal intrapartum antibiotic prophylaxis (IAP) is one of the most effective means to reduce early neonatal GBS diseases [1] though it has no effect on late onset infant diseases caused by GBS. Despite this, provision of IAP is not practiced at the University of Gondar Referral hospital particularly, and in Ethiopia generally. Thus, knowing of the status of maternal colonization, mainly in low-income courtiers like Ethiopia, is useful to device the preventive strategies.

Furthermore, there is a concern about the rise of antibiotic resistances among GBS isolates so that doing antibiotic susceptibility tests of such isolates before prescription is crucial [14] to test its susceptibility pattern. Antibiotic susceptibility testing (AST) of GBS isolates in South Africa depicted 100\% sensitive to penicillin, vancomycin and high level gentamicin $(120 \mu \mathrm{g})$. However, $21.1 \%$ were resistant to erythromycin and $17.2 \%$ to clindamycin. Of these, $69 \%$ had constitutive macrolide, lincosamide-streptogramin ${ }_{B}$ $\left(\mathrm{MLS}_{\mathrm{B}}\right)$, and $17.4 \%$ had inducible $\mathrm{MLS}_{\mathrm{B}}$. In addition, the $\mathrm{M}$ - and L-phenotypes were present in $6.8 \%$ each [15]. Of the 1160 isolates in Australia, 6.4\% revealed erythromycin resistance and $4.2 \%$ to clindamycin, and $53 \%$ of the erythromycin resistant isolates showed resistance to clindamycin [16]. Certain studies in Ethiopia indicated $36.4 \%$ to
$17 / 22$ (77.3\%) resistance to penicillin; $9.1 \%$ to $18.2 \%$ to clindamycin, and $4.5 \%$ to $22.6 \%$ to erythromycin $[2,17]$.

Maternal colonization prevalence, associated risk factors and its antimicrobial resistance patterns including inducible clindamycin resistance provide important information useful in devising prevention strategies in the area. Thus, the current study was aimed to determine maternal colonization prevalence, associated risk factors, and resistance patterns of GBS to the ten commonly prescribed antibiotics.

\section{Materials and methods Study setting}

The study was conducted at the University of Gondar Referral hospital, Northwest Ethiopia. It is one of the oldest hospitals in Ethiopia located $737 \mathrm{~km}$ away from Addis Ababa, Capital of Ethiopia. The hospital serves more than 5 million people and it has about 450 to 600 pregnant women admission services for delivery per month with two maternities (M1 and M2). During the study period, no routine screening of pregnant women and provision of IAP has been established in the hospital.

\section{Study design}

An institution based prospective cross-sectional study was conducted from 1st December 2016 to 30th November 2017.

\section{Source population and study population}

All pregnant women who attended at the University of Gondar Comprehensive Specialized hospital, Northwest Ethiopia, were the source population. Pregnant women who came for delivery at the maternity ward of the hospital with gestational age of $\geq 35$ weeks were the study population.

\section{Inclusion criteria}

Pregnant women, who consented for participation in the study, did not use vaginal cream, lubricants or traditional sterilizer (vinegar) and antibiotics in the last 2 weeks prior data collection; and those who were not in emergency room, not severely ill, mentally stable and had singleton were included in the study.

\section{Sample size determination}

The sample size was calculated by using the single population proportion estimation formula by taking $20.9 \%$ prevalence (p) of maternal colonization with GBS [3].

$$
n=\frac{z_{\alpha / 2}^{2} \times p(1-P)}{d^{2}}
$$

where; $\mathrm{n}=$ sample size, $\mathrm{p}=$ prevalence of neonatal colonization with GBS in Ethiopia $(p=50 \%), d=$ maximum 
allowable error (margin of error) $=0.05, Z=$ value of standard normal distribution (Z-statistic) at 95\% confidence level $(\mathrm{z}=1.96)$ and it became 254 pregnant women; however, to increase the precision/validity of the findings, the sample size was increased to 385 by taking $\mathrm{p}=50 \%$.

\section{Data collection}

Socio-demographic and biological data were collected from each pregnant woman who delivered at $\geq 35$ weeks of gestation at the maternity ward in the hospital until the pre-determined sample size was reached.

\section{Data collection tools Questionnaire}

A pretested questionnaire was used to collect data for assessment of socio-demography and to investigate the associated risk factors to maternal colonization with GBS. The questionnaire was prepared in English using published studies and translated into the local language (Amharic). Once data were collected, responses of each questionnaire were re-translated into English for analysis and report.

\section{Biological Specimen collection and culture processing}

A combined recto-vaginal swab was collected at the point of labor (before delivery) by using a sterile cotton applicator swab. Here, the lower third vagina was brushed followed by the rectal swab by the trained midwives following universal precautions [1] and was transported to the University of Gondar bacteriology laboratory within 2 to $4 \mathrm{~h}$ by using Amies transport medium and analyzed by following the methods described in the CDC and CLSI guidelines $[1,18]$. Swabs were placed in ToddHewitt selective enrichment broth supplemented with colistin $(10 \mu \mathrm{g} / \mathrm{ml})$ and nalidixic acid $(15 \mu \mathrm{g} / \mathrm{ml})$ (Cart Roth $\mathrm{GmbH}+\mathrm{Co}$. KG-Schoemperlensrr. 3-5-D-76185 Karlsruhe, Germany). The inoculated selective medium was incubated at $37{ }^{\circ} \mathrm{C}$ for $24 \mathrm{~h}$. Growth (turbidity) was sub-cultured onto $5 \%$ defibrinated sheep-blood agar (Oxoid, UK) and incubated for $24 \mathrm{~h}$ at $37{ }^{\circ} \mathrm{C}$ in $5 \% \mathrm{CO}_{2}$ atmosphere. All suspected colonies (with narrow hemolysis) were sub-cultured on nutrient agar and subjected to gram stain and catalase test. All gram positive cocci and catalase negative isolates were tested for CAMP factor for presumptive identification.

\section{CAMP (Christie-Atkins-Munch-Petersen) test}

CAMP test was used to differentiate GBS (CAMP positive) from Streptococcus pyogene (beta-hemolytic CAMP negative) by inoculating the known Staphylococcus aureus onto 5\% defibrinated sheep blood agar down the center of the plate with a wire loop. Group B
Streptococcus (test bacterium) was then streaked in a straight line perpendicular to the $S$. aureus within $2 \mathrm{~mm}$ far. The plate was then incubated at $35^{\circ} \mathrm{C}$ for $24 \mathrm{~h}$. A positive CAMP result was indicated by an arrowhead-shaped enhanced zone of beta-hemolysis in the area between the test organism and $S$. aureus with the arrow-point towards the $S$. aureus streak. The CAMP test positive colonies were presumptively considered as GBS.

\section{Antimicrobial resistance testing of Streptococcus agalactiae} All GBS identified were tested against ten antibiotics (Oxoid, Basingstoke, UK): penicillin G (P, 10IU), ampicillin (AMP, $10 \mu \mathrm{g}$ ), clindamycin (CLY, $2 \mu \mathrm{g}$ ), erythromycin $(\mathrm{E}, 15 \mu \mathrm{g})$, chloramphenicol $(\mathrm{C}, 30 \mu \mathrm{g})$, ciprofloxacin (CIP, $5 \mu \mathrm{g})$, ceftriaxone (CRO, $30 \mu \mathrm{g})$, vancomycin (VA, $30 \mu \mathrm{g}$ ), azithromycin (AZM, $15 \mu \mathrm{g}$, and tetracycline (TE, $30 \mu \mathrm{g}$ ) on $5 \%$ sheep blood containing Mueller-Hinton agar according to the Kirby-Bauer method (disk diffusion) following the CLSI criteria. Bacterial inocula were prepared by suspending 4 to 5 freshly grown GBS colonies in 3-5 ml sterile physiological saline and turbidity was adjusted to a 0.5 McFarland standard [18] used as a reference to adjust the bacterial suspension for antibiotic susceptibility test. Sterile cotton swab was dipped and rotated several times, and was pressed against wall of the test tube. It was then swabbed over the entire surface of the Muller-Hinton agar containing 5\% defibrinated sheep blood. Then, antibiotic impregnated paper disks were placed on the plate and incubated in $5 \% \mathrm{CO}_{2}$ atmosphere at $37{ }^{\circ} \mathrm{C}$ for $24 \mathrm{~h}$. Zone of inhibition around antibiotic disks was measured by calibrated ruler and interpreted as sensitive, intermediate or resistant by using standard chart [18].

\section{Detection of inducible clindamycin resistant Streptococcus agalactiae}

Clindamycin and erythromycin susceptibility and determination of different phenotypes of macrolide-lincosamide-streptogramin $_{\mathrm{B}}\left(\mathrm{MLS}_{\mathrm{B}}\right)$ resistance were performed by double-disk diffusion method on Mueller-Hinton agar (Biokar, France) containing 5\% sheep blood [18, 19]. Erythromycin $(15 \mu \mathrm{g})$ and clindamycin $(2 \mu \mathrm{g})$ disks (Oxoid) were placed $12 \mathrm{~mm}$ apart edge to edge [19]. After $24 \mathrm{~h}$ of incubation at $37{ }^{\circ} \mathrm{C}$, blunting of clindamycin inhibition zone proximal to erythromycin disk was taken as inducible $\mathrm{MLS}_{\mathrm{B}}$ resistance. Resistance to both clindamycin and erythromycin with no blunting of clindamycin inhibition zone indicated constitutive resistance. M-phenotype (efflux mechanism) was characterized by resistance to erythromycin but susceptibility to clindamycin with no blunting of inhibition zone around clindamycin disk. Eventually, susceptible to erythromycin but resistance to clindamycin was referred to as L-phenotype [19]. 


\section{Quality control}

Pre-test was done to check the questionnaire and the protocol for GBS identification. Data cleaning was done every day. Streptococcus agalactiae (ATCC 12386), Enterococcus faecalis (ATCC 29212); Streptococcus pyogenes (ATCC 19615), Staphylococcus aureus (ATCC 29213) and Escherichia coli (ATCC 25922) were used as quality control in this study.

\section{Definitions of terms}

Early onset disease: Diseases which appear from birth to 6th completed days.

Late onset disease: Diseases which appear in infants between the 1st week and 89 days of age.

Premature rupture of membrane (PROM), or pre-labor rupture of membrane: a rupture of membrane (breakage of the amniotic sac), commonly called breaking of the mother's water(s), more than $1 \mathrm{~h}$ before the onset of labor.

Preterm delivery: delivery before 37 completed weeks of pregnancy.

\section{Data analysis and interpretation}

Data were entered into excel spread sheet and exported to SPSS 20 (Chicago, IL, USA) and analyzed. Descriptive statistics aimed to summarize the study participants' characteristics across the outcome variable was used. Association between the outcome variable (colonization of pregnant women with GBS) and each independent variable (demography and clinical factors) was analyzed using bi-variable and multi-variable logistic regression model. All the variables were entered into the multivariable logistic regression using backward LR method to control the confounding effect. Explanatory variables which had significant association with the materna GBS colonization at a $p$ value $\leq 0.2$ in the bi-variable logistic regression model were entered to the multivariable logistic regression model to identify the risk factors associated to the colonization of pregnant women with GBS. Assumption of goodness of the model was checked by Hosmer-lemeshow test $(\mathrm{p}=0.828)$. Association between the outcome and the independent variables was calculated by using the adjusted odds ratio at a $\mathrm{p}$-value $\leq 0.05$ and $95 \%$ confidence interval.

\section{Results}

\section{Demography, obstetric characteristics and maternal colonization}

Among the total of 385 pregnant women, with $\geq 35$ gestational week of pregnancy, participated in our study, $77.1 \%$ were below the age of 25 years old, $82.9 \%$ were urban dwellers, and $74.3 \%$ were house wives. Almost half (49.1\%) of the participants were nullipara, $67.8 \%$ had four or more times of ANC follow up, 2.3\%, 4.8\% and 8.6\% had history of neonatal death, still birth and abortion respectively (Table 1).

The overall prevalence of colonization of pregnant women with GBS at the time of labour was 98/385 [25.5\% (95\% CI 21-29.5)]. Those pregnant women with $<25$ years old (19.22\%), urban dwellers (20.0\%), house wife (18.7\%), multiparity (15.21\%), and gestational age of pregnancy $\geq 37$ weeks $(25.19 \%)$ had higher prevalence of maternal colonization than their counterparts. A multivariable logistic regression analysis showed that those pregnant women who experienced meconium stained amniotic fluid were 3 times ( $\mathrm{AOR}=3.018,95 \%$ CI 1.225 , 7.437) more likely to have increased risk of colonization than their counterparts. In addition, the pregnant women who had longer duration of premature rupture of membrane/ROM were 2 times $(\mathrm{AOR}=1.897,95 \% \mathrm{CI} 1.014$, 3.417) more likely to have an increased risk of being colonized than those who had shorter duration of premature ROM (Table 1).

\section{Antimicrobial resistance profiles of Streptococcus agalactiae}

Among the 98 GBS isolates identified in our study, $10(10.2 \%)$ and $9(9.2 \%)$ of the isolates showed resistance to penicillin and ampicillin. The highest resistance was observed to tetracycline $72(73.4 \%)$ followed by 31 (31.6\%) to ceftriaxone, 26 (26.5\%) to erythromycin, and $21(21.4 \%)$ to clindamycin excluding inducible resistance (Tables 2, 3). Streptococcus agalactiae resistance to 0 (8.2\%), 1 (25.5\%) and 3 (39.8\%) or more antibiotics were also identified.

\section{Inducible clindamycin resistance (D-shape) of Streptococcus agalactiae}

The phenotypic analyses of 46 GBS results detected by double disc diffusion method are summarized in Table 3. Among the resistant and/or intermediate resistant isolates to erythromycin and clindamycin, $30.4 \%$ harboured L-phenotypes (lincosamide resistance); $28.3 \% \mathrm{M}$-phenotypes (efflux mechanism); 26.1\% constitutive $\mathrm{MLS}_{\mathrm{B}}$, and $15.2 \%$ inducible $\mathrm{MLS}_{\mathrm{B}}$.

\section{Discussion}

The prevalence of maternal colonization with GBS observed in our study was $25.5 \%$ (95\% CI $21-29.5 \%$ ). This much prevalence of maternal colonization with GBS may cause the presence of transmission of GBS from colonized pregnant women to neonates delivered from the GBS positive mothers in the study area and is useful to devise preventive strategies like IAP which is not yet practiced at the University of Gondar Referral hospital as well as in Ethiopia. Such a result is consistent with an 
Table 1 Maternal GBS colonization by demography and obstetric characteristics including multivariable analysis, Northwest Ethiopia $(\mathbf{n}=\mathbf{3 8 5})$

\begin{tabular}{|c|c|c|c|c|c|c|}
\hline Socio-demography & Classification & GBS $+, n^{\prime}=98, n(\%)$ & GBS-, n= 287, n (\%) & $\mathrm{COR}^{\mathrm{a}} ; 95 \% \mathrm{Cl}$ & $\mathrm{AOR}^{\mathrm{b}}, 95 \% \mathrm{Cl}^{\mathrm{c}}$ & p-value \\
\hline \multirow[t]{2}{*}{ Age (years) median $=25$ years } & $<25$ & $74(24.9)$ & $223(75.1)$ & 1 & - & - \\
\hline & $\geq 25$ & $24(27.3)$ & $64(72.7)$ & $1.130(0.660,1.935)$ & - & - \\
\hline \multirow[t]{2}{*}{ Residence } & Urban & $77(24.1)$ & $242(75.9)$ & 1 & - & - \\
\hline & Rural & $21(31.8)$ & $45(68.2)$ & $0.626(0.353,1.109)$ & - & - \\
\hline \multirow[t]{4}{*}{ Education } & Illiterate & $30(34.5)$ & $57(65.5)$ & $0.550(0.212,1.426)$ & - & - \\
\hline & Primary & $21(16.0)$ & $110(84.0)$ & $1.689(0.640,4.459)$ & - & - \\
\hline & Secondary & $40(29.2)$ & $97(70.8)$ & $0.738(0.293,1.857)$ & - & - \\
\hline & Tertiary & $7(23.3)$ & $23(76.7)$ & 1 & - & - \\
\hline \multirow[t]{3}{*}{ Occupation } & House wife & $72(25.2)$ & $214(74.8)$ & 1 & - & - \\
\hline & Employed & $21(28.4)$ & $53(71.6)$ & $0.849(0.479,1.504)$ & - & - \\
\hline & Others $^{d}$ & $5(20.0)$ & $20(80.0)$ & $1.346(0.487,3.716)$ & - & - \\
\hline \multirow[t]{2}{*}{ Gestational age (week) } & $<37$ & $1(33.3)$ & $2(66.7)$ & $0.681(0.061,7.590)$ & - & - \\
\hline & $\geq 37$ & $97(25.4)$ & $285(74.6)$ & 1 & - & - \\
\hline \multirow[t]{2}{*}{ Parity } & Multipara & $54(27.6)$ & $142(72.4)$ & $0.798(0.504,1.265)$ & - & - \\
\hline & Nullipara & $44(23.3)$ & $145(76.7)$ & 1 & - & - \\
\hline \multirow[t]{2}{*}{ History of still birth } & No & $94(25.6)$ & $273(74.4)$ & 1 & - & - \\
\hline & Yes & $4(22.2)$ & $14(77.8)$ & $1.205(0.387,3.752)$ & - & - \\
\hline \multirow[t]{2}{*}{ History of abortion } & No & $92(26.1)$ & $260(73.9)$ & 1 & - & - \\
\hline & Yes & $6(18.2)$ & $27(81.8)$ & $1.592(0.637,3.980)$ & - & - \\
\hline \multirow[t]{2}{*}{ History of neonatal death } & No & $93(24.7)$ & $283(75.3)$ & 1 & - & - \\
\hline & Yes & $5(55.6)$ & $4(44.4)$ & $0.263(0.063,1.000)$ & - & - \\
\hline \multirow[t]{2}{*}{ Gravidity } & Primigravida & $42(22.8)$ & $142(77.2)$ & 1 & - & - \\
\hline & Multigravida & $56(27.9)$ & $145(72.1)$ & $0.766(0.482,1.216)$ & - & - \\
\hline \multirow[t]{2}{*}{ Antenatal care (ANC) visit } & $0-3$ & $31(25.0)$ & $93(75.0)$ & $0.973(0.596,1.588)$ & - & - \\
\hline & $4-5$ & $67(25.7)$ & $194(74.3)$ & 1 & - & - \\
\hline \multirow[t]{2}{*}{ Contraceptive use } & No & $12(17.6)$ & $56(82.4)$ & 1 & - & - \\
\hline & Yes & $86(27.1)$ & $231(72.9)$ & $0.576(0.294,1.126)$ & - & - \\
\hline \multirow[t]{2}{*}{ Meconium stained amniotic fluid } & No & $92(27.4)$ & $244(72.6)$ & 1 & 1 & \\
\hline & Yes & $6(12.2)$ & $43(87.8)$ & $2.229(0.966,5.139)$ & $3.018(1.225,7.437)$ & 0.016 \\
\hline \multirow[t]{2}{*}{ History of preterm delivery } & No & $95(25.1)$ & $284(74.9)$ & 1 & - & - \\
\hline & Yes & $3(50.0)$ & $3(50.0)$ & $0.337(0.067,1.697)$ & - & - \\
\hline \multirow{2}{*}{$\begin{array}{l}\text { Chronic illness at current preg- } \\
\text { nancy }\end{array}$} & No & $90(24.8)$ & $273(75.2)$ & 1 & - & - \\
\hline & Yes & $8(36.4)$ & $14(63.6)$ & $0.905(0.344,2.382)$ & - & - \\
\hline \multirow[t]{2}{*}{$\mathrm{ROM}^{\mathrm{e}}$} & $\leq 1 \mathrm{~h}$ & $74(27.6)$ & $194(72.4)$ & 1 & 1 & \\
\hline & $>1 \mathrm{~h}$ & $24(21.1)$ & $90(78.9)$ & $1.313(0.781,2.378)$ & $1.897(1.014,3.417)$ & 0.033 \\
\hline \multirow[t]{2}{*}{ Duration of labor (hour) } & $4-12$ & $81(25.6)$ & $235(74.4)$ & 1 & - & - \\
\hline & $13-24$ & $17(24.6)$ & $52(75.4)$ & $1.054(0.577,1.927)$ & - & - \\
\hline \multirow[t]{2}{*}{ HIV status } & Negative & $94(25.3)$ & $278(74.7)$ & 1 & - & - \\
\hline & Positive & $4(30.8)$ & $9(69.2)$ & $0.761(0.229,2.528)$ & - & - \\
\hline
\end{tabular}

Italic values indicate significance of $p$-value $(p<0.05)$

${ }^{a}$ Crude odds ratio

b Adjusted odds ratio

c Confidence interval

d Student, daily laborer

e Rupture of membrane

overall recent estimate of maternal colonization reported in Africa (21.3\%), in sub-regions of Africa such as North
Africa (22.9\%), Middle Africa (23.9\%, and Southern Africa (28.9\%) [4]. Our result is also similar with various 
Table 2 Antibiotic resistance profiles for Recto-vaginal colonizing group B streptococcal isolates, Northwest Ethiopia

\begin{tabular}{llll}
\hline Antibiotics & \multicolumn{2}{l}{ GBS isolates $(\mathbf{n}=\mathbf{9 8})$} \\
\cline { 2 - 4 } & $\begin{array}{l}\text { Susceptible, } \mathbf{n} \\
\mathbf{( \% )}\end{array}$ & $\begin{array}{l}\text { Intermediate, } \\
\mathbf{n}(\%)\end{array}$ & Resistant, $\mathbf{n}$ (\%) \\
\hline Penicillin & $88(89.8)$ & $0(0.0)$ & $10(10.2)$ \\
Ampicillin & $89(90.8)$ & $0(0.0)$ & $9(9.2)$ \\
Erythromycin & $66(67.3)$ & $6(6.1)$ & $26(26.5)$ \\
Clindamycin & $72(73.5)$ & $5(5.1)$ & $21(21.4)^{\mathrm{a}}$ \\
Azithromycin & $76(77.6)$ & $3(3.1)$ & $19(19.4)$ \\
Vancomycin & $82(83.7)$ & $0(0.0)$ & $16(16.3)$ \\
Ceftriaxone & $67(68.4)$ & $0(0.0)$ & $31(31.6)$ \\
Ciprofloxacin & $84(85.7)$ & $0(0.0)$ & $14(14.3)$ \\
Chloramphenicol & $83(84.8)$ & $4(4.1)$ & $11(11.2)$ \\
Tetracycline & $19(19.4)$ & $7(7.1)$ & $72(73.4)$ \\
\hline
\end{tabular}

a Excluding the inducible clindamycin resistant isolates $\left(\mathrm{iMLS}_{\mathrm{B}}\right.$ )

studies conducted in different parts of the world that ranged from $20.9 \%$ in Ethiopia, Zimbabwe and Palestine $[3,20,21]$ to $28.7 \%$ in Poland [22]. However, it is lower than a report South Africa (48.2\%) [6]. Our study showed higher prevalence of maternal colonization with GBS than the adjusted worldwide estimates of colonization $(18 \%)$ with lower prevalence in sub-regions like Southern Asia (12.5\% and Eastern Asia (11\%) [4]; in India, 2.3\% [7] and 20\% in Democratic Republic of the Congo [23]. These discrepancies might be owing to the clinical characteristics, body site sampled, and time of screening for GBS. Accessibility of pregnant women screening for GBS, IAP provision, and detection techniques employed for GBS may also attribute for this variations. The latter could be justified by the fact that some studies used 5\% sheep blood agar (BAP); others used combination of enrichment selective culture media (ECM) and BAP, or $\mathrm{ECM} / \mathrm{PCR}$ (polymerase chain reaction) combination, serology or CAMP test [24]. Specimen storage conditions, duration of sample transportation, use of antibiotics and antiseptic products may also cause for disparities of GBS detection among studies. Swabbing cotton tips used, epidemiological characteristics, and different study designs might be the additional contributing reason for this variability across the studies.

Knowledge about risk factors associated to maternal colonization is useful to reduce morbidity and mortality related to GBS diseases. This study, found that socio-demography (age; occupation; educational status); obstetrics (antenatal visit; gravidity; gestational age; parity; history of still birth, preterm delivery, abortion, neonatal death, contraceptive use; chronic illness at current pregnancy including HIV; and duration of labor) did not associate to the maternal colonization like other various studies reported [3, 25-28]. Studies in Greece and Gambia found that increasing number of antenatal visits $[25$, 29], and midwife delivery were associated with maternal colonization [29]. Similarly, a study from Thailand revealed that older maternal age and lower gestational age were found to be the risk factors for maternal colonization [30]. Experiencing meconium stained amniotic fluid and length of premature ROM were significantly associated factors to maternal colonization in our study. The latter finding is supported by studies done in Nigeria and India $[28,31]$.

Streptococcus agalactiae resistance to penicillin, ampiciline, vancomycin, clindamycin and other tested antimicrobials is observed in the current study. This

Table 3 Macrolide, lincosamide-streptogramin B (MLSB) and inducible clindamycine resistance GBS isolates, Northwest Ethiopia $(n=46)$

\begin{tabular}{|c|c|c|c|c|c|c|c|c|}
\hline \multicolumn{9}{|l|}{ Double disc diffusion } \\
\hline \multirow[t]{2}{*}{ GBS phenotypes $^{\mathrm{a}}$} & \multicolumn{3}{|c|}{ Erythromycin (n) } & \multicolumn{3}{|c|}{ Clindamycin (n) } & \multirow[t]{2}{*}{ Total $(n=46)$} & \multirow[t]{2}{*}{ Percent (\%) } \\
\hline & $\mathbf{R}$ & 1 & $S$ & $\mathbf{R}$ & 1 & $S$ & & \\
\hline $\begin{array}{l}\text { Constitutive macrolide, lin- } \\
\text { cosamide-streptogramin } \\
\mathrm{B}\left(\mathrm{CMLS}_{\mathrm{B}}\right)\end{array}$ & 10 & 2 & - & 9 & 3 & - & 12 & 26.1 \\
\hline $\begin{array}{l}\text { inducible macrolide, lin- } \\
\text { cosamide-streptogramin } \\
\text { B ( } \mathrm{iMLS}_{\mathrm{B}} \text { ) }\end{array}$ & 6 & 1 & - & - & - & 7 & 7 & 15.2 \\
\hline M-phenotype & 10 & 3 & - & - & - & 13 & 13 & 28.3 \\
\hline L-phenotype & - & - & 14 & 12 & 2 & - & 14 & 30.4 \\
\hline D-shape positive & 6 & 1 & 0 & - & - & 7 & 7 & 15.2 \\
\hline D-shape negative & - & - & - & - & - & - & 39 & 84.8 \\
\hline
\end{tabular}

a CLSI disk diffusion breakpoints [18]. Erythromycin: $\geq 21 \mathrm{~mm}$, susceptible (S); 16 to $20 \mathrm{~mm}$, intermediate (I); $\leq 15 \mathrm{~mm}$, resistant (R). Clindamycin: $\geq 19 \mathrm{~mm}$, susceptible (S); 16 to $18 \mathrm{~mm}$, intermediate (I); $\leq 15 \mathrm{~mm}$, resistant (R) 
observation may help to alert the concerned bodies to minimize empirical therapy and to establish the antimicrobial stewardship in the study area. Similarly, reported resistance patterns to penicillin are different in different studies. Certain studies done in Ethiopia revealed that resistance to penicillin is ranged from 36.4 to $77.3 \%$ [2, 17] while others in same country showed no resistance to penicillin, ampicillin and/or vancomycin [3, 32, 33]. Worldwide studies also revealed nearly absence of pencillin, ampicillin and/or vancomycin resistant isolates; for example Tanzania [34]; Ghana [35]; South Africa [15]; China [36]; Brazil [37] and United Kingdom [38]. However, a recent data in Palestine showed $38.0 \%$ penicillin and $21.0 \%$ vancomycin resistance [21]. This showed that the magnitudes of resistance seen in the literatures are inconsistent with the observations of the current study. This variation might be due to the inadequacy of laboratory facilities and laboratory difficulties to do antibiotic resistance procedures for GBS in developing countries lead the physicians to treat patients empirically.

Significant number of GBS isolates showed erythromycin and clindamycin resistance in the current study. This may decrease the options for prophylaxis in pregnant women who are allergic to penicillin. A few studies conducted in Ethiopia demonstrated that 22.7\% GBS were resistant to erythromycin and $17.6 \%$ to $18.2 \%$ to clindamycin [17]. A South African study revealed that $21.1 \%$ of the isolates were resistant to erythromycin and $17.2 \%$ to clindamycin [15]. Another reports from Tanzania also indicated that $17.6 \%$ of GBS were resistance to clindamycin [34]; and $21.0 \%$ to clindamycin in USA [39]. These reports are in agreement with results of our study. However, we found higher resistance rate to erythromycin than the other studies conducted in same country $(6.9 \%$ to $11.8 \%)$ [3, 33]; $13.0 \%$ in Tanzania [34]; $8.62 \%$ and $8.1 \%$ in Brazil [37]. Different studies reported higher resistance rates that $45.2 \%$ to $50.7 \%$ resistance to erythromycin, and $36.7 \%$ (including D-test positives) to $38.4 \%$ to clindamycin in USA [40, 41]; $25.6 \%$ to erythromycin and $54.0 \%$ to clindamycin in Korea [42]; $43.0 \%$ to erythromycin and 69.0\% to clindamycin in Palestine [21]; and 66.2\% to erythromycin and $54.0 \%$ to clindamycin in China [36].

The highest antibiotic resistance rate was observed to tetracycline in our study (73.4\%). Similar resistance rates were reported in Tunisia (97.3\%) [43]; Iran (96\%) [44] and Palestine (45.0\%) [21]. Resistance rates to tetracycline, ceftriaxone, erythromycin and clindamycin observed in our study corroborates the resistance data to these antibiotics reported by Lambiase et al. and Emaneini et al. $[8,44]$. It might be caused by the widespread use of these antibiotics for different clinical cases that possibly leads to the emergence of antibiotic-resistance GBS.
A phenotypic analysis of the 46 erythromycin and/ or clindamycin resistant/intermediate GBS in our study revealed that $30.6 \%$ harboured L-phenotypes; $28.3 \%$ M-phenotypes; $26.1 \% \mathrm{CMLS}_{\mathrm{B}}$, and $15.2 \% \mathrm{iMLS}_{\mathrm{B}}$ phenotypes. Among the erythromycin and/or clindamycin resistance isolates analyzed in South Africa, 69\% had $\mathrm{CMLS}_{\mathrm{B}}$ and $17.4 \%$ had $\mathrm{iMLS}_{\mathrm{B}}$. The M- and L-phenotypes were present in $6.8 \%$ each [15]. A Tunisian report also showed that among erythromycin resistant isolates, $78.7 \%, 10 \%$ and $2.2 \%$ had $\mathrm{cMLS}_{\mathrm{B}}$, iMLS $\mathrm{B}_{\mathrm{B}}$, and M-phenotypes respectively [43]. Studies in Iran revealed that all the erythromycin resistant GBS had $\mathrm{CMLS}_{\mathrm{B}}$ [44] and $17.4 \%$ had $\mathrm{iMLS}_{\mathrm{B}}$ [45]. A study in USA reported that $8 \%$ had a positive D-test, indicating inducible clindamycin resistance [40]. Another study in USA also displayed 44\% $\mathrm{CMLS}_{\mathrm{B}}, 21 \% \mathrm{iMLS}_{\mathrm{B}}, 28 \% \mathrm{M}$-, and 6\% L-phenotype harbored isolates [39]. It is believed that the differences in antibiotics use, prophylaxis practice, widespread and indiscriminate use of these antibiotics in various clinical cases, variation in susceptibility test methods and/ or disparities in serotypes distribution may result to regional differences in resistance rates of GBS to different antibiotics.

\section{Conclusion}

The present study showed higher prevalence of maternal GBS colonization compared to previous Ethiopian studies. Meconium stained amniotic fluid and lengthy premature rupture of membrane were found to be the risk factors for maternal colonization. It also identified the presence of antimicrobial resistant GBS to penicillin, ampicillin, vancomycin, ceftriaxone and other tested antimicrobials. GBS with inducible clindamycin resistant were identified. Furthermore, L- M- and

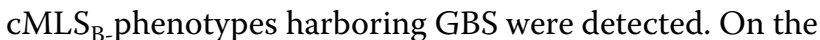
bases of the findings, pregnant women screening for GBS at their late third trimester, antibiotic susceptibility test before prescription, provision of intrapartum antibiotic prophylaxis, and large scale epidemiological studies have to be put into practice in the study area.

\section{Authors' contributions \\ MG participated in conception and design of the study, acquisition of data, analysis and interpretation of findings. BT participated in conception and design of the study, and interpretation of data; he also participated in revision of the manuscript. MT participated in design of the study, acquisition and interpretation data; in revision of the manuscript. FM participated in concep- tion of the study; and revision of the manuscript. MA participated in design of the study, and revision of the manuscript. ZT participated in interpretation of data, drafting and revision of the manuscript. All authors read and approved the final manuscript.}

\section{Author details}

${ }^{1}$ Department of Medical Microbiology, School of Biomedical and Laboratory Sciences, College of Medicine and Health Sciences, University of Gondar, P. O. Box 196, Gondar, Ethiopia. ${ }^{2}$ Department of Gynecology and Obstetrics, School 
of Medicine, College of Medicine and Health Sciences, University of Gondar, P. O. Box 196, Gondar, Ethiopia. ${ }^{3}$ Department of Pediatrics, School of Medicine, College of Medicine and Health Sciences, University of Gondar, P. O. Box 196, Gondar, Ethiopia.

\section{Acknowledgements}

The authors would like to acknowledge the financial and material support from the College of Medicine and Health Sciences, University of Gondar, Northwest Ethiopia, the German Academic Exchange Service (DAAD), Germany, and the Institute of Virology, Leipzig University, Germany. The authors are also grateful to the study participants'data collectors.

\section{Competing interests}

The authors declare that they have no competing interests.

\section{Availability of data and materials}

All data generated or analyzed during this study are included in this manuscript.

\section{Consent for publication \\ Not applicable.}

\section{Ethics approval and consent to participate}

It is done after we secured ethical approval from the institutional review board of the University of Gondar (R.No.O/N/P/RCS/05/478/2015 Mega project and O/N/P/RCS/05/471/2018). Permission was obtained from the University of Gondar Referral Hospitals administrative bodies. After giving a brief description about the purpose of the study, eligible mothers gave informed written consent for their participation in the questionnaire of this study and for their newborns to be a part of such a study. Confidentiality was ensured using code numbers than names and keeping the data locked in a cabinet, and using computer password.

\section{Funding}

Financial and material support were from the University of Gondar, Ethiopia, the German Academic Exchange Service (DAAD) In-Country scholarship and the Institute of Virology, Leipzig University, Germany for salary, material procurement, data collection, analysis, and interpretation and in writing the manuscript, printing and copying services.

\section{Publisher's Note}

Springer Nature remains neutral with regard to jurisdictional claims in published maps and institutional affiliations.

Received: 28 August 2018 Accepted: 10 January 2019

Published online: 19 January 2019

\section{References}

1. Centers for Disease Control and Prevention. Prevention of perinatal group B streptococcal disease: revised guidelines from CDC. MMWR. 2010;59(No. RR-10):1-36.

2. Woldu ZL, Teklehaimanot TG, Waji ST, Gebremariam MG. The prevalence of Group B streptococus recto-vaginal colonization and antimicrobial susceptibility pattern in pregnant mothers at two hospitals of Addis Ababa, Ethiopia. Reprod Health. 2014;11(80):1-4.

3. Mohammed M, Asrat D, Woldeamanuel Y, Demissie A. Prevalence of group B streptococcus colonization among pregnant women attending antenatal clinic of Hawassa Health Center, Hawassa, Ethiopia. Ethiop J Health Dev. 2012;26(1):36-42.

4. Russell NJ, Seale AC, Seale AC, O'Driscoll M, O'Sullivan C, Bianchi-Jassir F, Gonzalez-Guarin J, et al. Maternal colonization with group B streptococcus and serotype distribution worldwide: systematic review and meta-analyses. Clin Infect Dis. 2017;65(suppl_2):S100-11.

5. Seale AC, Koech AC, Sheppard AE, Barsosio HC, Langat J, Anyango E, et al. Maternal colonisation with Streptococcus agalactiae, and associated stillbirth and neonatal disease in coastal Kenya. Nat Microbiol. 2016;1(7):16067.
6. Lekala LM, Mavenyengwa RT, Moyo SR, Lebelo SL, Bolukaoto JY, Chukwu MO, et al. Risk factors associated with group B streptococcus colonization and their effect on pregnancy outcome. J Gynecol Obstet. 2015;3:121-8.

7. Sharmila V, Joseph NM, Babu TA, Chaturvedula L, Sistla S. Genital tract group B streptococcal colonization in pregnant women: a South Indian perspective. J Infect Dev Ctries. 2011;5(8):592-5.

8. Lambiase A, Agangi A, Del Pezzo M, Quaglia F, Testa A, Rossano F, et al. In vitro resistance to macrolides and clindamycin by group B streptococcus isolated from pregnant and non-pregnant women. Infect Dis Obstet Gynecol. 2012;2012:1-5.

9. Barcaite E, Bartusevicius A, Tameliene R, Kliucinskas M, Maleckiene L, Nadisauskiene R. Prevalence of maternal group B streptococcal colonization in European countries. Acta Obstet Gynecol Scand. 2008;87(3):260-71.

10. Seale AC, Bianchi-Jassir F, Russell NJ, Kohli-Lynch M, Tann CJ, Hall J, et al. Estimates of the burden of group B streptococcal disease worldwide for pregnant women, stillbirths, and children. Clin Infect Dis. 2017;65(suppl_2):S200-19.

11. Madzivhandila M, Adrian PV, Cutland CL, Kuwanda L, Schrag SJ, Madhi SA. Serotype distribution and invasive potential of group B streptococcus isolates causing disease in infants and colonizing maternal-newborn dyads. PLOS ONE. 2011;6(3):e17861.

12. Bergseng $H$, Bevanger $L$, Rygg $M$, Bergh $K$. Real-time $P C R$ targeting the sip gene for detection of group $B$ streptococcus colonization in pregnant women at delivery. J Med Microbiol. 2007;56:223-8.

13. Mavenyengwa RT, Moyo SR, Nordbø SA. Streptococcus agalactiae colonization and correlation with HIV-1 and HBV seroprevalence in pregnant women from Zimbabwe. Eur J Obstet Gynecol Reprod Biol. 2010;150:34-8.

14. Liddy H, Holliman R. Group B streptococcus highly resistant to gentamicin. J Antimicrob Chemother. 2002;50(1):42-3.

15. Bolukaoto JY, Monyama CM, Chuku MO, Lekala SM, Nechabeleng M, Maloba MRB, et al. Antibiotic resistance of Streptococcus agalactiae isolated from pregnant women in Garankuwa, South Africa. BMC Res Notes. 2015;8:364.

16. Garland SM, Cottrill E, Markowski L, Pearce C, Clifford V, Ndisang D, et al. Antimicrobial resistance in group B streptococcus: the Australian experience. J Med Microbiol. 2011;60(Pt 2):230-5.

17. Mengist HM, Zewdie O, Belew A, Dabsu R. Prevalence and drug susceptibility pattern of group B Streptococci (GBS) among pregnant women attending antenatal care (ANC) in Nekemte Referral Hospital (NRH), Nekemte, Ethiopia. BMC Res Notes. 2017;10:388.

18. Clinical and Laboratory Standards Institute. Performance standards for antimicrobial susceptibility testing. 27th ed. CLSI supplement M100. Wayne: Clinical and Laboratory Standards Institute. 2017;37(1):84-7.

19. Desjardins M, Delgaty KL, Ramotar K, Seetaram C, Toye B. Prevalence and mechanisms of erythromycin resistance in group $A$ and group $B$ streptococcus: implications for reporting susceptibility results. J Clin Microbiol. 2004;42(12):5620-3.

20. Mavenyengwa RT, Afset JE, Schei B, Berg S, Caspersen T, Bergseng H, et al. Group B streptococcus colonization during pregnancy and maternal-fetal transmission in Zimbabwe. Acta Obstet ricia et Gynecol. 2010;89:250-5.

21. El Aila NA, Esleem SE, Elmanama AA. Prevalence of group B streptococcus colonization among pregnant women in Gaza strip, Palestine. IUG J Nat Stud. 2017;25(3):1-12.

22. Romanik M, Nowosielski K, Poręba R, Sioma-Markowska U, Martiroisian G, Groborz J. Streptococcus group B serotype distribution in anovaginal isolates of women in term pregnancy. Neuro Endocrinol Lett. 2014;35(4):301-5.

23. Mitima KT, Ntamako S, Birindwa AM, Mukanire N, Kivukuto JM, Tsongo $\mathrm{K}$, et al. Prevalence of colonization by Streptococcus agalactiae among pregnant women in Bukavu, Democratic Republic of the Congo. J Infect Dev Ctries. 2014;8(9):1195-200.

24. Bakhtiari R, Dallal MS, Mehrabadi J, Heidarzadeh S, Pourmand M. Evaluation of culture and PCR methods for diagnosis of group $B$ streptococcus carriage in Iranian pregnant women. Iran J Public Health. 2012;41(3):65-70.

25. Tsolia M, Psoma M, Gavrili S, Petrochilou V, Michalas S, Legakis N, et al. Group B streptococcus colonization of Greek pregnant women and neonates: prevalence, risk factors and serotypes. Clin Microbiol Infect. 2003;9:832-8. 
26. Namugongo A, Joel Bazira J, Fajardot Y, Joseph N. Group B streptococcus colonization among pregnant women attending antenatal care at tertiary hospital in Rural Southwestern Uganda. Int J Microbiol. 2016;16:1-7.

27. Darabi R, Tadi S, Mohit M, Sadeghi E, Hatamizadeh G, Kardeh B, et al. The prevalence and RSK factors of group B streptococcus colonization in Iranian pregnant women. Electr Phys. 2017;9(5):4399-404 (ISSN: 2008 - 5842)

28. Onwuezobe IA, Effiom RA. Prevalence and associated risk factors of group B streptococcus in pregnant women attending antenatal care in a Nigerian urban hospital. Ibom Med J. 2016;9(1):1-7.

29. Le Doare K, Jarju S, Darboe S, Warburton F, Gorringe A, Heath PT, et al. Risk factors for group B streptococcus colonisation and disease in Gambian women and their infants. J Infect. 2016;72(3):283-94.

30. Kovavisarach E, Ying WS, Kanjanahareutai S. Risk factors related to group B streptococcal colonization in pregnant women in labor. J Med Assoc Thail. 2007;90(7):1287-92.

31. Patil KP, Singla SS, Nagmoti MB, Swamy MK. Group B Streptococci colonization in pregnant women: is screening necessary? J South Asian Feder Obstet Gynaecol. 2013;5(2):64-7.

32. Mengist A, Kannan H, Abdissa A. Prevalence and antimicrobial susceptibility pattern of anorectal and vaginal group B Streptococci isolates among pregnant women in Jimma, Ethiopia. BMC Res Notes. 2016;9:351.

33. Gebremeskel TK, Zeleke TA, Mihret A, Tikue MD. Prevalence and antibiotic susceptibility pattern of Streptococcus agalactiae among pregnant women at Adigrat Zonal Hospital and Adigrat Health Center, Tigray, Ethiopia. J Gynecol Obstet. 2015;3(2):29-35.

34. Joachim A, Matee MI, Massawe FA, Lyamuya EF. Maternal and neonatal colonisation of group B streptococcus at Muhimbili National Hospital in Dar es Salaam, Tanzania: prevalence, risk factors and antimicrobial resistance. BMC Public Health. 2009;9:437.

35. Vinnemeier CD, Brust P, Owusu-Dabo E, Sarpong N, Sarfo EY, Bio Y, et al. Group B Streptococci serotype distribution in pregnant women in Ghana: assessment of potential coverage through future vaccines. Trop Med Int Health. 2015;20(11):1516-24.
36. Lu B, Li D, Cui Y, Sui W, Huang L, Lu X. Epidemiology of Group B streptococcus isolated from pregnant women in Beijing, China. Clin Microbiol Infect. 2014;20:0370-3.

37. Melo SCCS, Santos NCS, Oliveira M, Scodro RBL, Cardoso RF, Pádua RAF, et al. Antimicrobial susceptibility of Streptococcus agalactiae isolated from pregnant women. Rev Inst Med Trop Sao Paulo. 2016;58:83.

38. Rao GG, Nartey G, McAree T, O'Reilly A, Hiles S, Lee T, et al. Outcome of a screening programme for the prevention of neonatal invasive early-onset group B Streptococcus infection in a UK maternity unit: an observational study. BMJ. 2017;7:e014634.

39. Gygax SE, Schuyler JA, Kimmel LE, Trama JP, Mordechai E, Adelson ME. Erythromycin and clindamycin resistance in group B streptococcal clinical isolates. Antimicrob Agents Chemother. 2006;50(5):1875-7.

40. Berg BR, Houseman JL, LeBar WD, Newton DW. Antimicrobial susceptibilities of group B Streptococcus isolates from prenatal screening samples. J Clin Microbiol. 2014;52(9):3499-500.

41. Back EE, O'Grady EJ, Back JD. High rates of perinatal group B Streptococcus clindamycin and erythromycin resistance in an upstate New York hospital. Antimicrob Agents Chemother. 2012;56:739-42.

42. Lee BK, Song YR, Kim MY, Yang JH, Shin JH, Seo YS, et al. Epidemiology of group B streptococcus in Korean pregnant women. Epidemiol Infect. 2010;138(2):292-8.

43. Hraoui M, Boubaker IBB, Rachdi M, Slim A, Redjeb SB. Macrolide and tetracycline resistance in clinical strains of Streptococcus agalactiae isolated in Tunisia. J Med Microbiol. 2012;61:1109-13.

44. Emaneini M, Mirsalehian A, Beigvierdi R, Fooladi AA, Asadi F, Jabalameli $F$, et al. High incidence of macrolide and tetracycline resistance among Streptococcus agalactiae strains isolated from clinical samples in Tehran, Iran. Maedica (Buchar). 2014;9:157-61.

45. Saffar H, Rajabiani A, Abdollahi A, Habibi S, Baseri Z. Frequency of inducible clindamycin resistance among gram-positive cocci in a tertiary hospital, Tehran, Iran. Iran J Microbiol. 2016;8(4):243-8.
Ready to submit your research? Choose BMC and benefit from:

- fast, convenient online submission

- thorough peer review by experienced researchers in your field

- rapid publication on acceptance

- support for research data, including large and complex data types

- gold Open Access which fosters wider collaboration and increased citations

- maximum visibility for your research: over 100M website views per year

At BMC, research is always in progress.

Learn more biomedcentral.com/submissions 